Revista Eletrônica do Mestrado em Educação Ambiental

\title{
Oficina de arte com sucata eletrônica: uma alternativa para a Educação Ambiental baseada na reutilização e aprendizagem criativa
}

\author{
Lis Ângela De Bortoli ${ }^{1}$ \\ Instituto Federal de Educação, Ciência e Tecnologia do Rio Grande do Sul - Campus Sertão \\ ORCID: http://orcid.org/0000-0001-9414-6569
}

Ana Sara Castaman ${ }^{2}$ Instituto Federal de Educação, Ciência e Tecnologia do Rio Grande do Sul - Campus Sertão ORCID: http://orcid.org/0000-0002-5285-0694

Resumo: O presente artigo tem por finalidade conhecer a relevância da reutilização, do upcycling e da aprendizagem criativa na educação ambiental, através de oficinas de arte com sucata eletrônica, de modo a apresentar um relato de experiência extensionista. Para tanto, pauta-se em abordagem qualitativa, a partir da técnica bibliográfica. Está dividido em 02 (duas) partes: a) versa sobre conceitos de e-lixo e as possibilidades do seu emprego para atividades de arte; b) aborda a experiência de promoção e de condução de oficinas de arte com sucata eletrônica enquanto atividade extensionista. Conclui-se que através das oficinas é possível construir aprendizagens acerca da reutilização de e-lixo, por meio do upcycling, bem como formar a autonomia, a criatividade e potencializar habilidades e competências mediante o uso de metodologia de aprendizagem criativa para educação ambiental.

Palavras-chave: Educação Ambiental; Extensão; Aprendizagem.

\section{Tallere de arte con desecho electrónico: una alternativa para la Educación Ambiental}

\section{basada en la reutilización y aprendizaje creativo}

Resumen: El propósito de este artículo es aprender la relevancia de la reutilización, el reciclaje y el aprendizaje creativo en la educación ambiental, a través de talleres de arte con chatarra electrónica, con el fin de presentar un informe de experiencia de extensión. Por lo tanto, se basa en enfoque cualitativo, basado en la técnica bibliográfica. Se divide en 02 (dos) partes: a) trata los conceptos de desechos electrónicos y las posibilidades de su uso para actividades artísticas; b) aborda la

\footnotetext{
${ }^{1}$ Bacharelado em Ciência da Computação pela UPF e Mestrado em Ciência da Computação pela UFRGS. E-mail: lis.debortoli@sertao.ifrs.edu.br

${ }^{2}$ Graduação em Pedagogia e Psicologia, Mestrado em Educação, Doutorado em Educação pela UNIS INOS. Docente no Prof. EPT. E-mail: ana.castaman@sertao.ifrs.edu.br
} 
experiencia de promover y realizar talleres de arte electrónico de desecho como una actividad de extensión. Se concluye que a través de los talleres es posible desarrollar el aprendizaje sobre la reutilización de los desechos electrónicos, a través del reciclaje, así como formar autonomía para la creatividad y mejorar las habilidades y competencias mediante el uso de una metodología de aprendizaje creativo para la educación ambiental.

Palabras clave: Educación ambiental; Extensión; Aprendizaje.

\title{
Art workshop with electronic scrap: an alternative for Environmental Education based on reuse and creative learning
}

\begin{abstract}
The purpose of this article is to learn the relevance of reuse, upcycling and creative learning in environmental education, through art workshops with electronic scrap, in order to present an extension experience report. Based on qualitative approach and a bibliographic technique, it is divided into 02 (two) parts: a) deals with e-waste concepts and the possibilities of its use for art activities; b) addresses the experience of promoting and conducting electronic scrap art workshops as an extension activity. It's concluded that through the workshops it's possible to build learning about the reuse of e-waste, through upcycling, as well as to form autonomy to creativity and to enhance skills and competences through the use of creative learning methodology for environmental education.
\end{abstract}

Keywords: Environmental education; Extension; Learning.

\section{Introdução}

A Extensão nas instituições educacionais possui um papel relevante no que concerne às suas contribuições à sociedade. Conforme Silva e Quimelli (2006), as atividades extensionistas são fundamentais para a oxigenação do conhecimento (artístico, científico, tecnológico e cultural) elaborado nas instituições de ensino superior. Além disso, permitem a interdisciplinaridade nas suas ações, colaborando à formação do estudante cidadão, ao trabalho a partir da realidade concreta, à cooperação para construção de uma sociedade melhor e à qualidade de vida da população.

Neste escopo, no Instituto Federal de Educação, Ciência e Tecnologia do Rio Grande do Sul (IFRS), a extensão visa o desenvolvimento socioeconômico, ambiental e cultural sustentável, local e regional de instituições, de segmentos sociais e do mundo do trabalho (IFRS, 2017). Para tanto, um dos projetos de extensão do IFRS - Campus Sertão, intitulado "E-lixo: ações de descarte, reutilização e educação ambiental" (DE BORTOLI, 2019), está voltado à temática da Educação Ambiental. Por educação ambiental entende-se os processos por meio dos quais o sujeito e a coletividade constituem valores sociais, atitudes, conhecimentos, habilidades, competências para a conservação do meio ambiente, assim como para a qualidade de vida e sua sustentabilidade (BRASIL, 1999). Reigota (1994), reforça que a escola constitui-se como um lócus privilegiado para a mediação de 
conhecimentos sobre e para a realização da educação ambiental, especialmente quando envolve ações criativas.

Assim, uma ação de educação ambiental do referido projeto é a promoção de oficinas de arte com sucata eletrônica, que tem por base a reutilização de materiais arrecadados em mutirões de coleta (outra ação do projeto). Pautadas no aproveitamento de resíduos eletroeletrônicos e no upcycling, que é o processo de criar algo novo a partir de itens descartados, as oficinas seguem também na linha do movimento maker e da aprendizagem criativa/significativa. Os artefatos produzidos nas oficinas, em geral, são produtos exclusivos, sustentáveis, feitos à mão e idealizados, individualmente ou em grupos, de maneira responsável. Dito isso, o objetivo das oficinas é demonstrar a possibilidade de reutilizar materiais que seriam descartados, na elaboração de novos produtos, com novas funções.

Destarte, este estudo de abordagem qualitativa, a partir da técnica bibliográfica, tem por finalidade conhecer a respeito da relevância da reutilização, do upcycling e da aprendizagem criativa/significativa na educação ambiental, através de oficinas de arte com sucata eletrônica, de modo a apresentar um relato de experiência extensionista. Está dividido em 02 (duas) partes: a) versa sobre conceitos de e-lixo e as possibilidades do seu emprego para atividades de arte; b) aborda a experiência de promoção e de condução de oficinas de arte com sucata eletrônica enquanto atividade extensionista.

\section{E-lixo e arte com sucata eletrônica}

Para a Associação Brasileira da Indústria Elétrica e Eletrônica ${ }^{3}$ (ABINEE, 2019), a indústria eletroeletrônica encerrou 2019 com faturamento de R\$ 154 bilhões, um crescimento nominal de 5\% em relação a 2018 (R \$ 146,1 bilhões), de acordo com dados projetados em dezembro de 2018. Esses dados demonstram que o setor de eletroeletrônicos está em franca ascensão, pois esse aumento vem se repetindo ao longo dos anos. Além disso, os avanços tecnológicos tornam os equipamentos eletroeletrônicos ultrapassados em uma velocidade muito rápida, o que faz aumentar o consumo de novos equipamentos, como celulares, computadores e eletrodomésticos (UNITED NATIONS, 2019). Os dispositivos rejeitados transformam-se em lixo eletrônico, sucata eletrônica, resíduo eletroeletrônico ou simplesmente e-lixo.

\footnotetext{
${ }^{3}$ Tem como missão assegurar o desenvolvimento competitivo do complexo elétrico e eletrônico do País e a defesa dos seus legítimos interesses e sua integração à comunidade
} 
Gerado por muitas fontes, incluindo residências, empresas e governos, lixo eletrônico é definido como algo que tenha um plugue, cabo elétrico ou bateria (incluindo equipamentos elétricos e eletrônicos), como por exemplo torradeiras, smartphones, geladeiras, laptops e televisores LED, que chegaram ao fim de sua vida útil, bem como os componentes que compõem esses produtos (UNITED NATIONS, 2019). Classificado como um tipo de resíduo sólido urbano, o e-lixo não deve ser jogado junto ao lixo comum, cujo destino são os lixões e os aterros sanitários pois, em geral, possuem em sua composição metais pesados e elementos químicos altamente tóxicos e nocivos à saúde, contaminando o solo, inclusive, podendo chegar ao lençol freático. Por desinformação, várias pessoas não conhecem os malefícios causados pelo destino inadequado do e-lixo, como descartar adequadamente esses resíduos e quais ações são possíveis de serem feitas em casa, no meio acadêmico e no trabalho.

Ainda, segundo a United Nations (2019), é possível encontrar, em sua composição, metais preciosos, como: ouro, cobre, níquel e materiais raros, como índio e paládio. Muitos desses metais podem ser recuperados, reciclados e utilizados como matérias-primas secundárias para novos produtos. O desafio é a alta complexidade desse processo, pois um produto pode ser composto por mais de mil substâncias diferentes. Até 60 (sessenta) elementos da tabela periódica podem ser encontrados em eletrônicos, como smartphones, muitos desses, sendo tecnicamente recuperáveis. Como a reciclagem é um processo ainda pouco explorado na área de eletroeletrônicos, pois apenas $20 \%$ destes materiais são reciclados (BALDÉ et al., 2017), a reutilização apresenta-se como alternativa de aproveitamento para esses equipamentos descartados.

Esses resíduos são consequência do consumismo descomedido, da obsolescência programada e da obsolescência perceptiva, ou seja, o fabricante "estabelece" uma espécie de validade ao equipamento, obrigando o consumidor a descartá-lo e, também, incentiva que os equipamentos eletroeletrônicos se tornem superados precipitadamente, por lançar sucessivas versões dos mesmos, em curto espaço de tempo. O nível de produção de e-lixo global deverá alcançar 120 milhões de toneladas ao ano em 2050 (NAÇÕES UNIDAS, 2019), se as tendências atuais permanecerem, de acordo com relatório da Plataforma para Aceleração da Economia Circular (PACE) e da Coalizão das Nações Unidas sobre Lixo Eletrônico. O relatório revela o valor anual de e-lixo global como superior a 62,5 bilhões de dólares, mais que o PIB de muitos países. Além disso, globalmente, a sociedade lida apenas com $20 \%$ de e-lixo adequadamente e existem poucos dados sobre o que acontece 
com os $80 \%$ restantes, sendo possível que a maior parte acabe depositada em aterros sanitários, ou seja, descartada por pessoas, em más condições (UNITED NATIONS, 2019).

Com isso, uma "sociedade de consumidores é impensável sem uma florescente indústria de remoção de lixo" (BAUMAN, 2008, p. 31). Segundo o Ministério do Meio Ambiente (BRASIL, [20--]), um caminho para minimizar os problemas relacionados com o lixo é apontado pelo Princípio dos 3R's - Reduzir, Reutilizar e Reciclar. Fatores associados com estes princípios devem ser considerados, como o ideal de prevenção e a não geração de resíduos, somados à adoção de padrões de consumo sustentável, visando poupar os recursos naturais e conter o desperdício.

Ainda, de acordo com o Ministério do Meio Ambiente (BRASIL, [20--]), reduzir sugere diminuir o consumo e escolher aqueles que ofereçam menor potencial de geração de resíduos e disponham de maior durabilidade. Reutilizar é usar novamente, reaproveitar algo como, por exemplo, uma embalagem ou uma peça, que tenha condições apropriadas de uso, em um contexto diferente do original. Reciclar, por sua vez, requer transformação dos materiais para a produção de matéria-prima para outros produtos, por meio de processos industriais ou artesanais.

Barbosa (2020), em notícia no site do Instituto Akatu, sugere a inclusão de mais um R, que deve ser praticado antes dos 3Rs originais, o Repensar. Esse ato significa refletir sobre as ações de consumo e as repercussões que elas geram sobre as pessoas, a economia, as relações sociais e a natureza.

Destaca-se também que, em 2010, a Presidência da República, por meio da Casa Civil, instituiu a Política Nacional de Resíduos Sólidos (PNRS), na forma da lei No 12.305 , de 2 de agosto. A referida lei dispõe sobre os seus princípios, objetivos e instrumentos, bem como as diretrizes relativas à gestão integrada e ao gerenciamento de resíduos sólidos, incluídos os perigosos, as responsabilidades dos geradores e do poder público e aos instrumentos econômicos aplicáveis (BRASIL, 2010). O art. $8^{\circ}$ do referido documento, destaca os instrumentos da PNRS como sendo, entre outros:

[...] III - a coleta seletiva, os sistemas de logística reversa e outras ferramentas relacionadas à implementação da responsabilidade compartilhada pelo ciclo de vida dos produtos; IV - o incentivo à criação e ao desenvolvimento de cooperativas ou de outras formas de associação de catadores de materiais reutilizáveis e recicláveis; [...] VI - a cooperação técnica e financeira entre os setores público e privado para o desenvolvimento de pesquisas de novos produtos, métodos, processos e tecnologias de gestão, reciclagem, reutilização, tratamento de resíduos e disposição final ambientalmente adequada de rejeitos; VII - a pesquisa 
científica e tecnológica; VIII - a educação ambiental; [...] (BRASIL, 2010).

Ao abordar a educação ambiental no espaço escolar almeja-se preservar o seu potencial crítico, refletindo a partir de uma perspectiva político-pedagógica e inserindo para além da macrotendência conservadora, a crítica (LAYRARGUES, 2012). Esta última problematiza as desigualdades ambientais, de modo a contribuir na transformação social, na construção de aprendizagens por parte dos participantes de uma consciência ambiental e na formação criativa e autônoma dos mesmos.

Assim, uma das formas de fomentar a educação ambiental rumo à transformação social, de elaborar alternativas de prevenção e de conservação do meio ambiente, tem sido a criação de propostas de arte com sucata eletrônica. Paula et al. (2006, p. 14) enfatiza que, "[...] a Arte é parte integrante da realidade social, é elemento de estrutura de tal sociedade e expressão da prática social e espiritual do homem”. Ferraz e Fusari (1993, p. 16) reforçam que "o fundamental portanto, é entender que a Arte se constitui de modos específicos de manifestação da atividade criativa dos seres humanos ao interagirem com o mundo em que vivem [...]”. Argan (2005, p. 15) marca sobre as obras de arte e a sua relação no tempo e no espaço,

Cada obra não é apenas resultado de um conjunto de relações, mas determina, por sua vez, um campo de relações que se estendem até o nosso tempo e o superam, uma vez que, assim como certos fatos salientes da arte exerceram uma influência determinante mesmo à distância de séculos, também não se pode excluir que sejam considerados como campo de referência num futuro próximo ou distante.

Logo, a arte ao estar associada à sucata envolve criatividade e comunicação por meio de inúmeras linguagens, amparadas no equilíbrio e no respeito ao meio ambiente. Palhaci et al. (2012, p. 555) aludem que "No século XXI intensifica-se o pensamento ambiental e a reciclagem alia-se a arte com o intuito de reaproveitamento de materiais através de diferentes formas artísticas".

Inúmeros artistas estão utilizando materiais recicláveis para produzir obras e, ao mesmo tempo, incentivando a reutilização. Como exemplo, a artista plástica brasileira Naná Hayne utiliza resíduos de computadores (cabos, placas e outras peças) para criar obras de arte. Hayne transforma o lixo eletrônico em painéis, esculturas e acessórios como as tecnojoias (NANÁHAYNE, 2016). Chiapetta ([20--]) apresenta um texto com vertentes sobre a arte ambiental. 
$\mathrm{Na}$ educação, a arte com sucata tem promovido propostas de ensino, de pesquisa e de extensão que questionam os conceitos econômicos, sociais e políticos em cena e, também, difundem ideias cooperativas e sustentáveis. A educação por intermédio da arte com sucata eletrônica contribui para que o estudante compreenda o mundo da vida:

Trabalhar com projetos exige uma reflexão constante e é por meio dela que podemos avaliar todos os passos planejados e já realizados, para dar sequência às ações. Essas ações depois de operadas e recriadas na própria ação, serão refletidas para nova avaliação e replanejamento. O trabalho do ensinante está pautado em ação-reflexão-ação (MARTINS; PICOSQUE; GUERRA, 1998, p. 155).

Diante do exposto, a próxima seção aborda as oficinas de arte com sucata eletrônica, enquanto uma experiência extensionista.

\section{Oficinas de arte com sucata eletrônica: uma experiência extensionista}

Na concepção do IFRS, a Extensão é definida como um processo educativo, cultural, social, científico e tecnológico que promove a interação entre as instituições, os segmentos sociais e o mundo do trabalho, com ênfase na produção, no desenvolvimento e na difusão de conhecimentos científicos e tecnológicos, visando ao desenvolvimento socioeconômico, ambiental e cultural sustentável, local e regional (IFRS, 2019). Além disso, no contexto do IFRS, a ação extensionista é compreendida enquanto uma

[...] prática acadêmica que liga a instituição nas suas atividades de ensino e pesquisa com as demandas das comunidades de alcance de suas unidades. Ela deve contribuir para a formação de um profissional cidadão e se torna um espaço privilegiado de produção e disseminação do conhecimento, priorizando a superação das desigualdades sociais (IFRS, 2019, p. 05).

O IFRS, por meio da Política de Extensão, objetiva:

I - promover o desenvolvimento de atividades extensionistas de acordo com os princípios e finalidades da Educação Profissional, Científica e Tecnológica, em articulação como mundo do trabalho e os segmentos sociais;

II - promover uma inserção qualificada das ações de extensão nos cursos da Instituição, numa perspectiva interdisciplinar e indissociável das atividades de ensino e pesquisa;

III - estimular e apoiar processos educativos que levem à geração de trabalho e renda e à emancipação do cidadão na perspectiva do desenvolvimento socioeconômico sustentável, local e regional; 
IV - propiciar a participação institucional em ações sociais que priorizem a superação da desigualdade e a melhoria da qualidade de vida, no âmbito das ações afirmativas;

$\mathrm{V}$ - incentivar o desenvolvimento de programações científicas, artísticoculturais, sociais e esportivas, envolvendo os estudantes, servidores e a sociedade;

VI - promover a transferência de tecnologias sociais, notadamente àquelas voltadas à preservação do meio ambiente;

VII - apoiar a produção cultural, o empreendedorismo e o cooperativismo;

VIII - estimular ações de extensão vinculadas ao desenvolvimento sustentável e às ações afirmativas;

IX - intensificar as relações com instituições públicas, privadas e organizações sociais para a realização de parcerias nacionais e internacionais; e,

$\mathrm{X}$ - estabelecer estratégias institucionais para assegurar o atendimento às dimensões da extensão, às suas diretrizes e à implementação de políticas públicas (IFRS, 2019, p. 02).

A extensão na instituição está pautada em diretrizes que se constituem em orientações para a elaboração, a avaliação e a implementação das ações extensionistas com base na interação dialógica, na interdisciplinaridade e interprofissionalidade, na indissociabilidade ensino-pesquisa-extensão, no impacto na formação do estudante e na transformação social. As ações de extensão, articuladas com o ensino e a pesquisa de forma indissociável, devem ser desenvolvidas sob a forma de programas, projetos, cursos, eventos ou prestação de serviços. Os projetos de extensão são formalizados com finalidade específica e prazo determinado, visando ao resultado de mútuo interesse para a sociedade e para a comunidade acadêmica (IFRS, 2019).

As ações de extensão são classificadas em áreas temáticas, cuja intenção é propiciar o diálogo dos extensionistas, bem como possibilitar estudos e relatórios de maneira a subsidiar a implementação de políticas de fomento à extensão. Atualmente as áreas temáticas são: comunicação, cultura, direitos humanos e justiça; educação, meio ambiente, saúde, tecnologia e produção e trabalho.

Sendo assim, com foco no descarte, na reutilização e na educação ambiental, foi elaborado e executado, desde 2011, um projeto de extensão no IFRS - Campus Sertão, com objetivo de conscientizar a comunidade externa e interna, por meio de ações de educação ambiental, sobre o lixo eletroeletrônico produzido e a importância de um destino adequado para estes equipamentos (DE BORTOLI, 2019). O projeto conta com a participação de bolsistas de extensão, que são estudantes devidamente matriculados em cursos oferecidos pelo Campus. Devido à temática do projeto, é dada a preferência aos estudantes inscritos nos cursos de Tecnologia em Análise e Desenvolvimento de Sistemas, Licenciatura em 
Ciências Biológicas, Tecnologia em Gestão Ambiental e Técnico em Manutenção e Suporte em Informática.

Dentre as ações de caráter educativo, ambiental, social, cultural, científico e tecnológico efetivadas junto à comunidade, destacam-se: oficinas de arte com sucata eletrônica, palestras/bate-papos sobre descarte de lixo, exposições do E-Museu ${ }^{4}$, mutirões de coleta de resíduos eletroeletrônicos, oficinas de jogos educativos sobre o descarte de lixo e exposições de artefatos confeccionados com sucata eletrônica.

No que concerne à oficina, Anastasiou e Alves (2006) caracteriza como uma estratégia de ensino, marcada por uma reunião, com um número pequeno de pessoas, mas com interesses comuns, sob a orientação de um especialista. Essa ação permite aprender a fazer melhor algo, diante da aplicação de conceitos e de conhecimentos previamente internalizados. Vieira e Volquind (1996, p. 12) aludem que as oficinas devem integrar três dimensões: pensar, agir e fazer. Estes campos devem estar em equilíbrio para permitir um espaço de aprendizagem.

A proposta de oficinas necessita criar um espaço para a vivência, a reflexão e a construção de conhecimentos. Não é somente um lugar para aprender fazendo: supõe, principalmente, o pensar, o sentir, o intercâmbio de ideias, a problematização, o jogo, a investigação, a descoberta e a cooperação.

Neste caso, as oficinas de arte com sucata eletrônica (DE BORTOLI; BRANDALISE; MONTEMEZZO, 2018) foram realizadas entre 2015 e 2019, em escolas de ensino fundamental de Sertão $^{5}$ (cidade e interior), eventos como a Geek Week e Seminário do Grêmio Estudantil dos Cursos Técnicos do Campus Sertão (GETECS), Unidade Curricular de Educação Ambiental no IFRS - Campus Sertão, Projeto Segundo Tempo em Tapejara/RS e Seminário Nacional de Inclusão Digital (SENID), em 2018, em Passo Fundo/RS. No total foram 8 (oito) oficinas, com a participação de 223 pessoas, no período supracitado.

As oficinas de arte com sucata eletrônica, promovidas pelos integrantes do projeto de extensão E-Lixo, são idealizadas seguindo basicamente três etapas principais: planejamento, execução e avaliação. No planejamento, normalmente com o apoio da Prefeitura Municipal de Sertão, parceira do projeto, é feito o agendamento com a instituição na qual será oferecida a oficina, a preparação dos materiais que serão utilizados

\footnotetext{
${ }^{4}$ Museu itinerante que exibe equipamentos que tiveram papel relevante na história dos eletroeletrônicos.

${ }^{5}$ O município de Sertão está localizado no norte do Rio Grande do Sul, distante aproximadamente 320 quilômetros da capital Porto Alegre e possui uma estimativa de população de 5.415 habitantes (IBGE, 2020).
} 
e, com base no público-alvo, a elaboração de uma apresentação para ser utilizada no início da oficina. Essa apresentação, criada em meio digital, inclui tópicos e imagens marcantes, que revelam a problemática do lixo eletroeletrônico, bem como os impactos do descarte inadequado, tanto para o meio ambiente como para saúde humana. Na execução da oficina, a apresentação digital deu-se a partir da estratégia metodológica expositivo-dialogada, de argumentações e de questionamentos acerca do tema. Dependendo dos recursos disponíveis, faz-se uso de vídeos que refletem a temática.

A origem dos materiais empregados na elaboração dos artefatos são objetos descartados nos Mutirões de Coleta de Lixo Eletrônico, realizados anualmente pelo projeto $^{6}$. Utilizando equipamentos de proteção individual como luvas e óculos, os bolsistas do projeto fazem a triagem dos materiais rejeitados e separam aqueles que podem ser reutilizados. Se necessário, as peças são desmontadas com a utilização de kits de ferramentas e furadeira, e limpas, sendo que somente peças não tóxicas e que não ofereçam risco ao serem manuseados são operacionalizadas, como por exemplo, teclados, CDs/DVDs, disquetes, baterias, fios, memórias, caixas de som, mouses, gabinetes, Hard Disks (HDs), coolers, leitores de DVD. Todo o material que não é aproveitado no projeto é encaminhado para a empresa Recycle, que faz a destinação ambientalmente adequada dos resíduos. Localizada em Passo Fundo/RS e parceira do projeto desde o primeiro Mutirão de Coleta, a Recycle é uma empresa de gestão de resíduos sólidos, especializada em lixo eletroeletrônico. Sem custos para o projeto, a empresa parceira responsabiliza-se por buscar o material descartado e dar o devido destino.

A fim de auxiliar na composição dos artefatos, em menor escala, permite-se também o uso de outros resíduos descartados, como papelão, embalagens do tipo PET, rolhas, arames, fitas, pinhas, latas, pedaços de madeira e de vidro. Ocasionalmente, recorre-se ao Setor de Marcenaria do Campus para o corte e o arremate dos materiais e, opcionalmente, para dar acabamento às peças, emprega-se tinta, verniz spray, papel EVA, caneta de escrita permanente e cola instantânea especial. Dependendo das peças a serem elaboradas, adquirem-se a baixo custo, suportes para chaveiros e brincos, aros de anel, ímãs, alfinetes para bottons, entre outros.

Em suma, a prática utilizada na preparação dos materiais, baseia-se no upcycling e na reinserção nos processos produtivos de materiais que teriam como único destino o lixo, para criar novos produtos. O upcycling, também conhecido como reuso criativo, envolve o

\footnotetext{
${ }^{6}$ Através dos Mutirões de Coleta já foram arrecadados aproximadamente vinte e três toneladas de e-lixo.
} 
uso de materiais originalmente criados para um fim, na criação de algo diferente. Desta forma, é possível usar sucata eletrônica para criar beleza, arte e funcionalidade. Diferentemente da reciclagem, que envolve a transformação de material através do uso de processos físicos e químicos, o objetivo do upcycling é transformar aquilo que está no fim do ciclo de vida, em algo novo (LOPES; PADILHA; SCHULTE, 2014). Fazer upcycling pode ser uma maneira de exercitar a criatividade e também ajudar a preservar e conservar o meio ambiente. Com essa abordagem é possível manter o valor de um produto usado e, em vez de jogar fora, pode-se criar algo novo com valores estéticos mais altos; resíduos rejeitados podem ser valorizados e atualizados (ALI; KHAIRUDDIN; ZAINAL ABIDIN, 2015). Para Sung (2015), o upcycling é considerado como um processo no qual os resíduos são convertidos em algo de maior valor e/ou qualidade, em uma segunda vida, e tem sido cada vez mais reconhecido como um meio promissor de reduzir uso de material e energia. O upcycling vem crescendo significativamente, visto que é ecologicamente correto e possui um custo bastante reduzido (SAFFI, 2015).

$\mathrm{Na}$ execução da oficina, o primeiro passo é a adaptação do espaço, normalmente uma sala de aula. São distribuídas classes e cadeiras, de forma a estimular e a permitir a prática de trabalho em pequenos grupos. Para que seja possível atender adequadamente os participantes, o número de vagas é limitado $^{7}$, observando também a faixa etária. Ao receber os participantes, é realizada a apresentação elaborada na etapa de planejamento, sendo os bolsistas responsáveis pelo acompanhamento dos grupos e a coordenadora do projeto pela supervisão geral. Salienta-se que as oficinas são de temática livre, baseadas em alguma data comemorativa ou tema específico, como por exemplo: robôs, artefatos de suporte ou enfeites, aviões.

As peças são dispostas nas mesas (Figura 1), sendo permitido aos participantes a busca e a pesquisa de ideias para criação dos artefatos em sites, através de seus smartphones. Antes de iniciar o manuseio das peças, os bolsistas explicam ao grupo o significado de cada uma delas, bem como o seu papel no funcionamento do computador, evidenciando assim um viés à inclusão digital, que pode ser apontado como um diferencial. Para De Luca (2004, p. 09) "a inclusão digital deve favorecer a apropriação da tecnologia de forma consciente, que torne o indivíduo capaz de decidir quando, como e para que utilizá-la". Assim, entende-se que a inclusão digital vai além do acesso ao computador, da conexão à internet e do manuseio de softwares. Por isso, o intuito é instigar a curiosidade

\footnotetext{
${ }^{7}$ Utiliza-se como parâmetro 15 a 20 participantes.
} 
sobre conceitos que não fazem parte do rol de saberes oferecidos pelas escolas. Ao entender a base e os princípios de seu funcionamento, os participantes percebem que o computador não é simplesmente uma caixa composta de placas e de circuitos eletrônicos, mas sim, um instrumento poderoso de processamento de dados.

Figura 1 - Disposições das peças

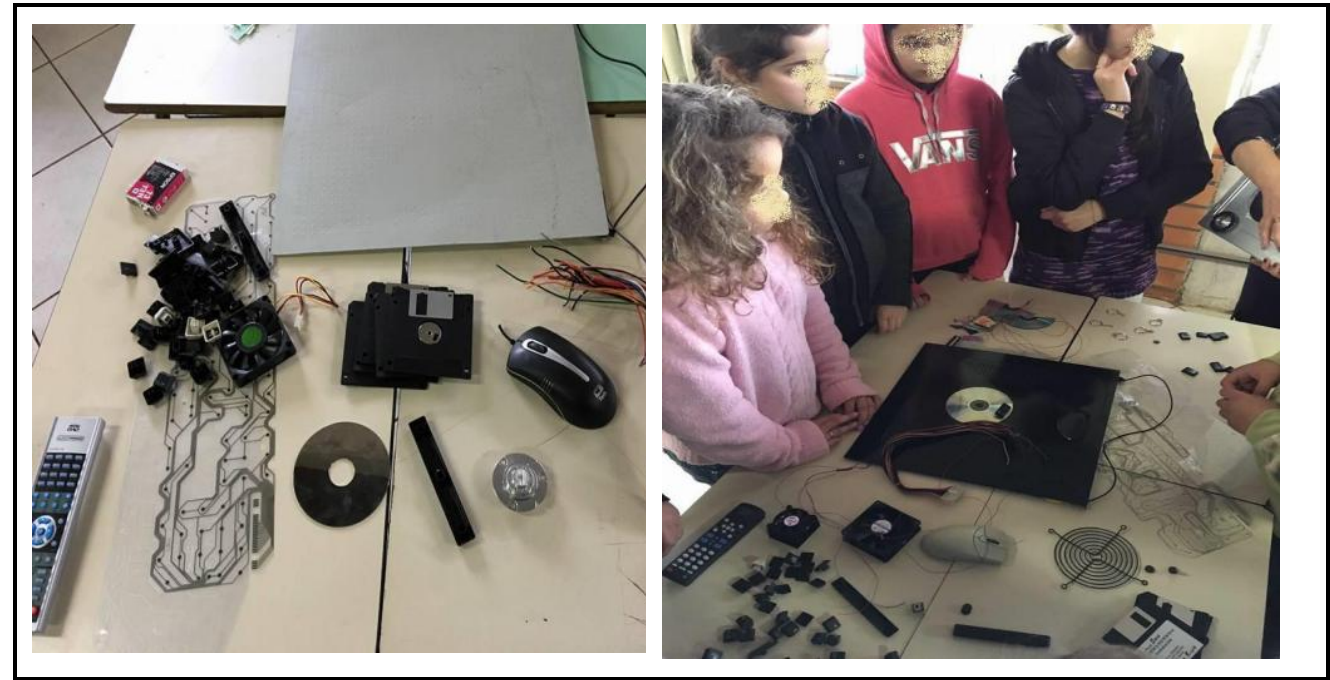

Fonte: Autoras, 2019.

Em seguida, solicita-se ao grupo que idealize, projete, reflita e construa o artefato, ressaltando a importância do planejamento e da sua intencionalidade antes da construção, pois uma vez coladas, as peças não poderão ser desencaixadas facilmente. Dessa forma, além da prática de educação ambiental, são enfatizados conceitos relevantes como o trabalho colaborativo, a autonomia, a criatividade, o consenso, a iniciativa, a flexibilidade, o comprometimento e a comunicação oral.

Durante as oficinas, são empreendidas, de forma significativa e criativa, discussões sobre os temas relacionados ao meio ambiente e a reutilização, objetivando a reflexão e a elaboração de sugestões sobre problemas elencados na conversa. Sendo assim, constata-se que ao aprender, os participantes também se divertem, demonstram empolgação e envolvimento, para alcançar um resultado concreto. Deste modo, durante as oficinas percebeu-se e aplicou-se os 4P's (Projects, Peers, Passion, Play), da aprendizagem criativa ou Creative Learning (RESNICK, 2014). A Figura 2 demonstra os participantes realizando atividades durante as oficinas.

Figura 2 - Participantes realizando atividades durante as oficinas 


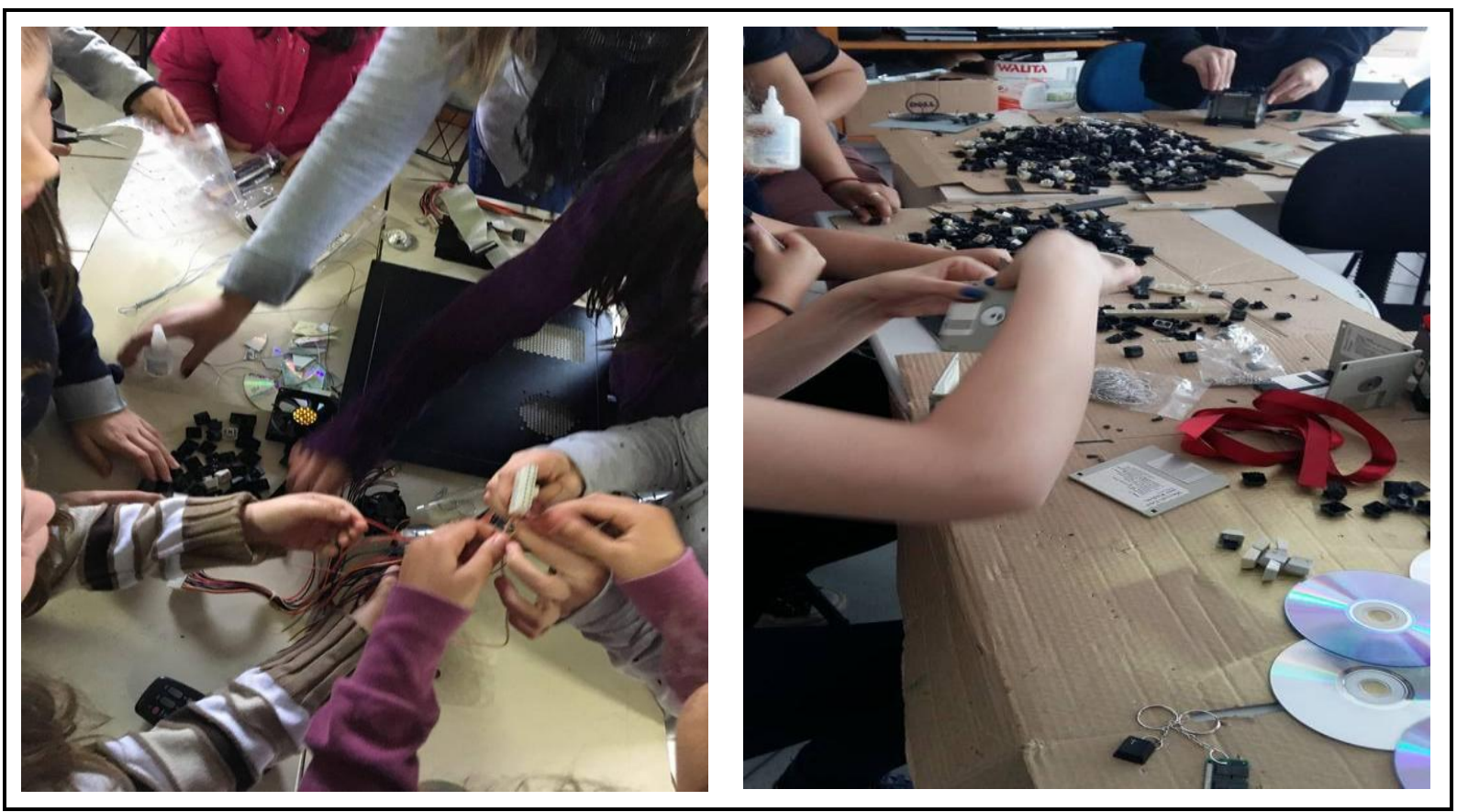

Fonte: Autoras, 2019

A Aprendizagem Criativa é uma abordagem pedagógica que tem por finalidade uma experiência mais criativa, relevante e lúdica (RESNICK, [20--]). Os participantes vão descobrindo e construindo caminhos e soluções no desenvolvimento do projeto, por meio de um pensamento e de um trabalho pedagógico criativo. Este construcionismo é abordado por Papert e Harel (1991), enquanto uma condição para que o aprendiz conscientemente engajado possa construir algo compartilhável, independente do que for.

Ainda, muitas vezes, os participantes expressam que gostaram do resultado, mas que a ideia inicial era outra, que poderiam ter feito melhor ou de outra forma, que se enganaram ao colar uma peça, demonstrando que o erro pode ser valorizado. $\mathrm{O}$ fundamental é que cada participante de forma coletiva e colaborativa colocou a mão na massa para resolver a atividade, o que fortaleceu a possibilidade de criação, tanto no plano coletivo, como no da autonomia pessoal. "O trabalho colaborativo é essencial na aquisição de outras habilidades importantes. Após saírem da escola, a maioria dos estudantes encontrará, no mundo do trabalho, situações nas quais eles precisam partilhar informações e trabalhar produtivamente com os outros" (LOPES et al., 2019, p. 63).

Salienta-se ainda que, para além da construção de um artefato, fomenta-se a construção da aprendizagem (BEINEKE, 2014) e a formação da autonomia e da criatividade. Pois educar é colocar fim à separação entre Homo faber e Homo sapiens; é resgatar o sentido estruturante da educação e de sua relação com o trabalho e com as suas possibilidades criativas e emancipatórias (BOMFIM et al., 2017). Para o autor, transformar 
essas ideias e esses princípios em práticas concretas é uma tarefa que exige ações para além dos espaços das salas de aula, dos gabinetes e dos fóruns acadêmicos. Assim, enfatiza-se a consonância dos objetivos das oficinas com um dos desafios da Educação Profissional e Tecnológica (EPT), que é fazer uma educação para além do ambiente acadêmico, de modo a manter uma relação com a sociedade e estabelecer bases humanísticas na formação dos indivíduos, atendendo o princípio educativo número um dos Institutos Federais de Educação, Ciência e Tecnologia (IF), que é a formação integral (BOMFIM et al., 2017, PACHECO, 2020). A Figura 3 mostra alguns dos artefatos ${ }^{8}$ produzidos nas oficinas.

Figura 3 - Artefatos produzidos

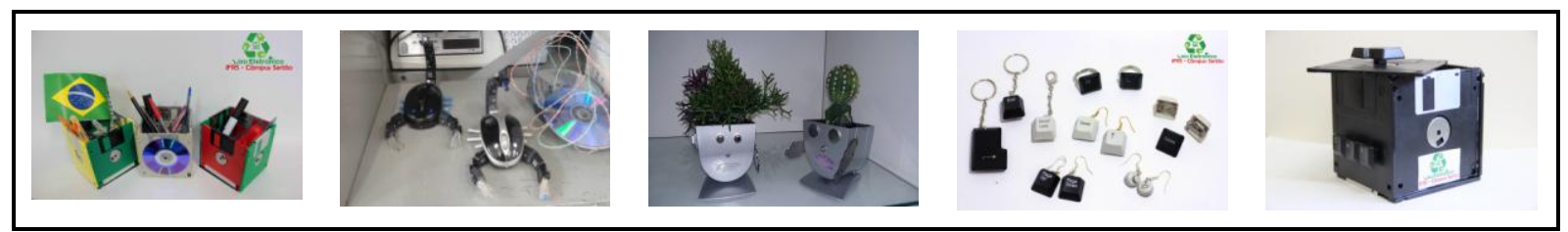

Fonte: Autoras, 2019.

Outro ponto relevante remete à avaliação das oficinas, que acontece de modo processual. Porém, ao encerrar cada oficina, incentiva-se que os participantes avaliem a mesma, com o intuito de verificar suas impressões acerca da atividade, bem como apontar possibilidades de melhoria na sua condução. O registro da avaliação é feito por meio de fotos, vídeos e áudios, que são gravados a partir de depoimentos dos participantes e de seus professores, que eventualmente acompanham a atividade. Como forma de incentivo, os artefatos criados são deixados em exposição nas escolas ou podem ser levados pelos participantes para suas residências.

Conforme a Figura 3, os artefatos produzidos são únicos e exclusivos, utilizando peças descartadas: disquetes tornaram-se porta-trecos e porta-chás; mouses, teclas e cabos de rede viraram objetos decorativos; caixas de som, baterias e ímãs de HD converteram-se em vasos de plantas; teclas transformaram-se em chaveiros, anéis, bottons e brincos. Sendo assim, fica demonstrada a possibilidade do upcycling com sucata eletrônica, que conforme Morelli (2017), é um processo que atua sobre o material descartado sem depreciá-lo, aumenta o aproveitamento, altera aspectos estéticos e funcionais, agrega valor e prolonga a vida útil.

\footnotetext{
${ }^{8}$ Uma variedade de artefatos pode vista na página do projeto: https://www.facebook.com/lixoeletronicoifrs/
} 
Por fim, embora não abordado de maneira aprofundada, salienta-se que no ensino, as oficinas também tiveram um papel importante nas aulas do componente curricular Educação Ambiental, do Curso Técnico em Manutenção e Suporte em Informática, modalidade concomitância externa, do IFRS - Campus Sertão. Com carga horária de 20h semanais e posicionada no quinto semestre do curso, a unidade curricular tem por objetivo geral

Proporcionar a busca de uma ação holística na área ambiental, para sua aplicação na educação ambiental de forma: multi, inter, e transdisciplinar, contribuindo em programas diversos, em uma atividade integrada de reflexão constante, em relação a própria cientificidade de uma dada prática de pesquisa, e em relação aos resultados das diversas ciências, sem romper com a especificidade do olhar ecológico (IFRS, 2013, p. 43).

Pautada em introduzir os conceitos de meio ambiente e realizar práticas de educação ambiental, a professora e também coordenadora do projeto E-Lixo, abordou temas mais voltados para a área do curso e utilizou a oficina como prática pedagógica. A experiência permitiu aos estudantes uma aproximação maior ao problema da geração de resíduos eletroeletrônicos, contribuindo também para sua formação como cidadãos.

\section{Considerações finais}

O consumismo desmedido, aliado à obsolescência programada e perceptiva são os principais fatores que influenciam no aumento da quantidade de e-lixo, tanto no Brasil, quanto no Mundo. Além disso, a Indústria Brasileira de eletroeletrônicos está em clara expansão, indicando que essa área continuará em crescimento. O lixo eletroeletrônico é nocivo para a saúde humana e para o meio ambiente, pois contém substâncias tóxicas e elementos químicos com alto potencial poluente. $\mathrm{O}$ descarte adequado desses equipamentos é um dos fatores que podem minimizar os impactos ao meio ambiente. Ademais, por meio da reutilização e do upcycling, é possível aumentar a vida útil dos equipamentos descartados, o que contribui significativamente para a diminuição da quantidade de e-lixo.

Como alternativa ao problema da geração desses resíduos, apresentou-se neste trabalho, a ação extensionista de educação ambiental, através de oficinas de arte com sucata eletrônica. Averiguou-se que a intencionalidade educativa das oficinas foi cumprida, uma vez que, a partir das mesmas, os estudantes puderam debater e construir conhecimentos acerca da área ambiental, além de fomentar o trabalho em equipe, a 
colaboração, a socialização, a criatividade, entre outros. Ainda, percebeu-se que, por meio das oficinas de arte com sucata eletrônica, com foco na reutilização, no upcycling e na aprendizagem criativa, foi possível reorientar a extensão para uma educação ambiental baseada no desenvolvimento sustentável e construção de aprendizagens que conduzam à consciência ambiental e à formação criativa e autônoma.

A aprendizagem criativa provou ser um caminho interessante para uma educação ambiental, com mais sentido aos envolvidos na extensão. Entendeu-se neste trabalho pedagógico extensionista que, por esta visão, pode-se fomentar a criação, o pensamento criativo e a autonomia dos participantes. Esta concepção está em consonância com os princípios educativos dos IF, principalmente no que tange à formação humana integral e à indissociabilidade entre todas as dimensões do processo educativo (Ensino, Pesquisa e Extensão).

Embora não tenha sido escopo deste artigo, as oficinas também foram utilizadas como prática pedagógica, no curso Técnico em Manutenção e Suporte em Informática em parceria com o projeto E-Lixo, bem como foram realizados levantamentos de dados, evidenciando a articulação do ensino com a extensão e a pesquisa. Dessa forma, a experiência aqui relatada demonstrou a oportunidade e a viabilidade da reutilização e do upcycling de materiais e de componentes eletroeletrônicos, sendo pretensão futura, o aprofundamento dos estudos através do desenvolvimento de outros projetos indissociáveis, que venham a aprimorar e/ou complementar as práticas educativas já adotadas. Assim, ainda que não investigados profundamente o ensino e a pesquisa em educação ambiental nesta experiência, ressalta-se a possibilidade de, em outros momentos, realizar produções científicas abordando também essas dimensões.

\section{Referências}

ABINNE. Relatório Anual 2019 da Associação Brasileira da Indústria Elétrica e Eletrônica. Disponível em

<http://www.abinee.org.br/programas/imagens/rel2019/2/\#zoom=z>. Acesso em 22 jun. 2020.

ALI, Nawwar Shukriah; KHAIRUDDIN, Nuur Farhana; ZAINAL ABIDIN, Shahriman. Upcycling: re-use and recreate functional interior space using waste materials. 2015 Disponível em: https://www.researchgate.net/publication/269932497_Upcycling_Reuse_and_recreate_functional_interior_space_using_waste_materials. Acesso em 20 mai 2020. 
ANASTASIOU, Léa das Graças Camargos; ALVES, Leonir Pessate (Org.) Processos de ensinagem na universidade: pressupostos para as estratégias de trabalho em aula. 6 . ed. Joinville: Univille, 2006. p. 79-99.

ARGAN, Giulio Carlo. História da arte como história da cidade. 5. ed. São Paulo: Martins Fontes, 2005.

BALDÉ, Cornelis Peter et al. The Global E-waste Monitor 2017 Quantities, Flows, and Resources. 2017. Disponível em: https://www.itu.int/en/ITU-D/ClimateChange/Documents/GEM\%202017/Global-E-waste\%20Monitor\%202017\%20\%20Executive\%20Summary.pdf. Acesso em: 30 mai. 2020.

BARBOSA, Maiara. Akatu é parceiro da Rede Globo em campanha do Meio Ambiente. 2020. Disponível em: https://www.akatu.org.br/noticia/akatu-e-parceiro-darede-globo-em-campanha-do-meio-ambiente/ Acesso em: 23 jun. 2020.

BAUMAN, Zygmunt. Vida para consumo: a transformação das pessoas em mercadorias. Rio de Janeiro: Jorge Zahar Ed., 2008.

BEINEKE, Viviane. Aprendizagem criativa na escola: um olhar para a perspectiva das crianças sobre suas práticas musicais. Revista da ABEM, v.19, n. 26, 2014.

BRASIL. Lei $\mathbf{n}^{\circ}$ 9.795, de 27 de abril de 1999. Dispõe sobre a educação ambiental, institui a política nacional de educação ambiental e dá outras providências. Disponível em: http://www.planalto.gov.br/ccivil_03/leis/19795.htm Acesso em: 06 ago. 2019.

BRASIL. Política Nacional de Resíduos Sólidos. Lei nº 12.305, de 2 de agosto de 2010, que institui a Política Nacional de Resíduos Sólidos. Disponível em:

http://www.planalto.gov.br/ccivil_03/_ato2007-2010/2010/lei/l12305.htm. Acesso em: 23 jun. 2020.

BRASIL. Ministério Do Meio Ambiente. Princípio do 3 R's. [20--]. Disponível em $<$ https://www.mma.gov.br/responsabilidade-socioambiental/producao-e-consumosustentavel/consumo-consciente-de-embalagem/principio-dos-3rs.html>. Acesso em 18 jun. 2020.

BOMFIM, Alexandre Maia do et al. As políticas públicas e o papel social dos Institutos Federais de Educação, Ciência e Tecnologia. Série Reflexões na Educação, v 1, 2017. Disponível em: https://memoria.ifrn.edu.br/bitstream/handle/1044/1510/SE\%CC\%81RIE\%20REFLEXO\% CC\%83ES\%20NA\%20EDUCAC\%CC\%A7A\%CC\%830\%20\%20v\%201.pdf?sequence=1\&isAllowed=y;. Acesso em: 27 jun. 2020.

CHIAPETTA, Marina Santos. Arte e meio ambiente: grandes vertentes e poderes questionadores. Ecycle. [20--]. Disponível em: https://www.ecycle.com.br/3961-arte-emeio-ambiente-ambiental-sustentavelsustentabilidade? $1 b=$ no\&fbclid=IwAR11vN9HwZedS6ML5VZ11cJEi1_OA5CbgxN59t812 ghNEL93Sza2YA7zh48. Acesso em: 25 jun. 2020. 
DE BORTOLI, Lis Ângela; BRANDALISE, Ana Paula; MONTEMEZZO, Henrique.

Reutilizando e-lixo através de arte com sucata eletrônica. $1^{\circ}$ Congresso Sul Americano de Resíduos Sólidos e Sustentabilidade. Anais[...]. Gramado/RS. 12 a 14 de junho de 2018. Disponível em: http://www.ibeas.org.br/conresol/conresol2018/III-006.pdf. Acesso em: 12 jun. 2020.

DE BORTOLI, Lis Ângela. Projeto de Extensão E-lixo: ações de descarte, reutilização e educação ambiental. Instituto Federal de Educação, Ciência e Tecnologia do Rio Grande do Sul - Campus Sertão. 2019. (Mimeo).

DE LUCA, Cristina. O que é Inclusão Digital? In: CRUZ, Renato. O que as empresas podem fazer pela inclusão digital. São Paulo: Instituto Ethos, 2004.

FERRAZ, Maria Heloísa C. de T.; FUSARI, Maria F. de Rezende e. Metodologia do ensino de arte. São Paulo: Cortez, 1993.

IBGE. Instituto Brasileiro de Geografia e Estatística. Panorama. 2020. Disponível em: https://cidades.ibge.gov.br/brasil/rs/sertao/panorama Acesso em: 22 jun. 2020.

IFRS. Instituto Federal de Educação, Ciência e Tecnologia do Rio Grande do Sul Campus Sertão. Projeto Pedagógico Do Curso Técnico Em Manutenção E Suporte Em Informática. Julho, 2013. (Mimeo)

IFRS. Instituto Federal de Educação, Ciência e Tecnologia do Rio Grande do Sul. Política de Extensão do Instituto Federal De Educação, Ciência e Tecnologia do Rio Grande do Sul. Resolução $\mathrm{n}^{\circ}$ 058, de 15 de agosto de 2017. Disponível em: https://ifrs.edu.br/wpcontent/uploads/2017/08/Resolucao_058_17_Completa.pdf. Acesso em: 17 out. 2019.

IFRS. Instituto Federal de Educação, Ciência e Tecnologia do Rio Grande do Sul. Cartilha da Pró-Reitoria de Extensão do IFRS: extensão em ação. 2019. (Mimeo).

LAYRARGUES, Philippe Pomier. Para aonde vai a educação ambiental? O cenário político-ideológico da educação ambiental brasileira e os desafios de uma agenda política crítica contra-hegemônica. Revista Contemporânea de Educação, v. 7, n. 14, p. 388-411, ago.-dez., 2012.

LOPES, Luciane Dornbusch; PADILHA, Lucas da Rosa Mayeni Medeiros; SCHULTE, Neide Köhler. Logística reversa, reutilização e trabalho social na moda. Moda Palavra eperiódico, v. 7, n. 13, jan./jun. 2014. Disponível em:

http://www.revistas.udesc.br/index.php/modapalavra/article/view/5119/3317. Acesso em: 25 jun. 2020.

LOPES, Renato Matos et al. Características gerais da aprendizagem baseada em problemas. In: LOPES, Renato Matos; SILVA FILHO, Moacelio Veranio; ALVES, Neila Guimarães. Aprendizagem baseada em problemas: fundamentos para a aplicação no ensino médio e na formação de professores. Rio de Janeiro: Publiki, 2019.

MARTINS, Mirian Celeste; PICOSQUE, Gisa; GUERRA, M. Teresinha Telles. Teoria e prática do ensino de arte: a língua do mundo. São Paulo: FTD, 1998. 
MORELLI, Graziela; ENDER, Jaqueline. Upcycling: um novo caminho para a moda sustentável. 2017. $6^{\circ}$ GAMPI Plural, Joinville/SC. Disponível em: http://pdf.blucher.com.br.s3-sa-east1.amazonaws.com/designproceedings/gampi2017/12.pdf. Acesso em: 30 mai. 2020.

NANÁHAYNE. Tecnojóias. 2016. Disponível em: http://nanahaynearte.blogspot.com/ Acesso em: 23 jun. 2020.

NAÇÕES UNIDAS. Mundo produzirá 120 milhões de toneladas de lixo eletrônico por ano até 2050, diz relatório. 2019. Disponível em: <https://nacoesunidas.org/mundoproduzira-120-milhoes-de-toneladas-de-lixo-eletronico-por-ano-ate-2050-diz-relatorio/> . Acesso em: 10 jun. 2020.

PACHECO, Eliézer. Desvendando os Institutos Federais: identidade e objetivos. Educação Profissional e Tecnológica em Revista, Vitória, v. 4, n. 1, 2020. Disponível em: https://ojs.ifes.edu.br/index.php/ept/article/view/575. Acesso em: 27 jun. 2020.

PALHACI, Maria do Carmo Jampaulo Plácido et al. A importância da arte como meio de reciclagem e como formação de um novo pensamento ambiental. V World Congress on Communication and Arts. Guimarães/Portugal, de 15 a 18 de Abril de 2012. Disponível em: https://repositorio.unesp.br/bitstream/handle/11449/134942/ISSN23171707-2012-05-01-553-557.pdf?sequence=1. Acesso em: 24 jun. 2020.

PAPERT, Seymour; HAREL, Idit (org.). Constructionism: Research, Reports and Essays, 1985-1990. Massachusetts: Ablex, 1991.

PAULA, Carlos Alberto de et al. Arte: quem tem uma explicação. In: VÁRIOS AUTORES. Arte. Curitiba: SEED Paraná, 2006.

REIGOTA, Marcos. Meio ambiente e representação social. São Paulo: Cortez, 1994.

RESNICK, Michel. Give P's a chance: Projects, Peers, Passion, Play. In: Proceedings of Constructionism and Creativity Conference, Vienna, Austria, 2014.

RESNICK, Michel. Acredito que a escola (na verdade, toda a vida) deveria se tornar mais como o jardim de infância. [20--]. Disponível em:

https://www.voltaasaulas.aprendizagemcriativa.org/o-que-e-aprendizagem-criativa Acesso em: 26 jun. 2020.

SAFFI, Beatriz. Brasília escala humana: upcycling com tecido descartado para a marca Pau-Brasília. 2015. 129 f. Monografia (Bacharelado em Desenho Industrial), Universidade de Brasília, Brasília, 2015.

SILVA, Soraya Petla; QUIMELLI, Gisele A. de Sá. A extensão universitária como espaço de formação profissional do assistente social e a efetivação dos princípios do projeto éticopolítico. Emancipação, v. 6, n. 1, p. 279-296, 2006.

SUNG, Kyungeun. A review on upcycling: current body of literature, knowledge gaps and a way forward. Proceedings of the 17th International Conference on Environment, Cultural, Economic and Social Sustainability. Anais [...]. Venice, 13-14 April 2015, pp. 
28-40. Disponível em: https://dora.dmu.ac.uk/handle/2086/14640. Acesso em 25 Jun. 2020 .

UNITED NATIONS. A New Circular Vision for Electronics Time for a Global Reboot. 2019. Disponível em

http://www3.weforum.org/docs/WEF_A_New_Circular_Vision_for_Electronics.pdf. Acesso em: 23 maio 2020.

VIEIRA, Elaine; VOLQUIND, Lea. Oficinas de Ensino: O quê? Por quê? Como?. Porto Alegre: EdiPUCRS, 1996.

Submetido em: 29-06-2020.

Publicado em: 18-12-2020. 